\title{
Entrevista com Maurizio Lazzarato ${ }^{1}$
}

\author{
Gustavo Bissoto Gumiero ${ }^{2}$
}

Maurizio Lazzarato, filósofo e sociólogo italiano, é um dos maiores críticos do capitalismo da atualidade. Em sua juventude, na Itália, estudou Ciências Políticas na Università di Padova e participou ativamente da autonomia operaia, movimento de grandes lutas operárias que ocorreram principalmente no norte da Itália, demonstrando seu forte engajamento político. Forçado a se exilar na França, em 1982, lá começava uma nova etapa em sua vida. Depois de ter exercido diversos tipos de trabalho nos primeiros anos - para ele, duros no sentido econômico, mas divertidos do ponto de vista de experiência de vida -, ingressava na Université Paris 8. A partir de então, Lazzarato será cada vez mais influenciado pelo pensamento da dupla de pensadores Gilles Deleuze e Félix Guattari, cujo resultado aparecerá em suas obras mais recentes, como Signos, máquinas, subjetividades. ${ }^{3}$ No Brasil, sua pesquisa é conhecida de forma segmentada, parcelar. Suas únicas obras publicadas até 2010 eram Trabalho imaterial ${ }^{4}$ e As revoluções do capitalismo, ${ }^{5}$ cujas páginas estão longe de representar a plenitude

\footnotetext{
${ }^{1}$ Recebido em 14/09/2015 e aprovado em 03/04/2016.

2 Doutorando em Sociologia pela Universidade Estadual de Campinas (Unicamp). Contato: gustavo.gumiero@gmail.com.

${ }^{3}$ LAZZARATO, M. Signos, máquinas, subjetividades. Trad. Paulo Domenech Oneto. São Paulo: N-1/SESC-SP, 2014.

${ }^{4}$ LAZZARATO, M.; NEGRI, A. Trabalho imaterial: Formas de vida e produção de subjetividade. Trad. Monica de Jesus Cesar. Rio de Janeiro: DP\&A, 2001.

${ }^{5}$ LAZZARATO, M. As revoluções do capitalismo. Trad. Leonora Corsini. Rio de Janeiro: Civilização Brasileira, 2006.
} 
do pensamento mais recente de Lazzarato. Sobre o conceito do "trabalho imaterial", largamente discutido no Brasil, é necessário salientar que foi usado somente em seus primeiros escritos, e nunca mais retomado pelo autor, que recusa fortemente a ideia dos desdobramentos posteriores de tal conceito, como "trabalho cognitivo".

A entrevista a seguir, originalmente em italiano, foi realizada em 9 de julho de 2015, por meio de conferência Skype.

Gustavo Bissoto Gumiero: Onde e em que ano o senhor nasceu?

Maurizio Lazzarato: Nasci em uma pequena cidade que se chama Meduna di Livenza, província de Treviso, Vêneto, ${ }^{6}$ Itália, em 1955.

GBG: Como se deu a sua chegada e participação na autonomia operaia italiana?

ML: No início dos anos 1970, existiam movimentos por toda a Itália e nós nos organizamos em vários pequenos grupos em nossas pequenas cidades de dois, três mil habitantes. Sou filho de operários, e por isso conheci muita gente. E então eu tinha uma relação com alguns grupos da autonomia. Depois, enquanto meus amigos foram trabalhar, eu entrei na universidade.

GBG: Qual universidade?

ML: Università di Padova. Eu fiz Ciências Políticas.

\footnotetext{
${ }^{6}$ A região do Vêneto, no nordeste da Itália, é uma das mais ricas daquele país e compõe, junto com as regiões da Lombardia e Piemonte, o "coração industrial" do país.
} 
GBG: Foi na Universidade de Padova que começou a amizade com Antonio Negri?

ML: Na realidade, Negri não era militante [da autonomia operaia] em Padova. Lá ele era somente professor. Ele era militante em outra cidade, em Milão, e por isso não tinha nenhuma relação. E eu também era muito jovem, tinha cerca de 22 anos a menos que Toni [Negri], e era militante da autonomia cuja base estava em Padova, e por isso não conhecia Toni pessoalmente.

GBG: E que marcas pessoais e intelectuais a participação na autonomia deixou na sua vida?

ML: Foi muito importante, pois eu comecei a estudar, militar, e era um movimento muito forte na Itália naquele período. Eu já tinha percorrido uma certa estrada para a política anteriormente, mas foi lá que isso se realizou e, fundamentalmente, permaneci sempre muito fiel a esse princípio da militância - mesmo se depois, aqui na França, não fiz uma verdadeira militância política, sempre permaneci ligado a essa história.

GBG: E por que o senhor teve que fugir da Itália no início dos anos 80 ?

ML: Eu tinha um mandado de busca por formação de quadrilha e associação subversiva, e sabendo disso, escapei para a França, pois o [François] Mitterrand tinha dado a possibilidade de um asilo político, e por isso eu cheguei aqui [na França] em 1982. 
GBG: E quando chegou na França, o que mudou na sua vida?

ML: Algumas coisas, porque fundamentalmente se tratava de uma derrota política. E depois também as dificuldades de viver aqui. Por muitos anos, exercemos diversos tipos de trabalho, em obras etc., e foi somente no fim dos anos 80 e início dos anos 90 que voltei a trabalhar de novo teoricamente, porque Toni [Negri] também chegou e reconstruiu um pouco os círculos de discussão; mas por seis, sete anos o meu problema era como sobreviver.

GBG: Foram, então, anos duros?

ML: Sim, duros, mas também tranquilos. Para dizer a verdade, eu me diverti. Duros do ponto de vista econômico, mas como éramos jovens, não é que fosse muito pesado para nós, pois nos bastava pouco. E descobrimos um outro mundo. A fase anterior [na Itália], do ponto de vista político, estava fechada, e não sabíamos muito bem o que fazer.

GBG: E com quem o senhor morava na França?

ML: Com colegas italianos. No início, assim que chegamos, não conhecíamos ninguém, mas existia uma forte solidariedade entre nós e alguns franceses nos ajudaram, por isso ficamos unidos em grupo por muitos anos.

GBG: E nos anos 90 foi extinto o mandado de busca?

ML: Sim, o processo foi anulado, não existia mais o mandado de prisão do grupo. 
GBG: E depois desses primeiros sete, oito anos na França, o senhor começou a estudar e chegou a conhecer Deleuze e Guattari? Como foi esse processo intelectual?

ML: Não conheci o Deleuze. O Guattari era mais próximo, ajudou muito os italianos. Eu ia aos seminários dele, mas não entendia nada do que ele contava na época. Ele tinha a revista Chimères. Eu ia aos seminários e depois participava do grupo de discussão, mas não posso dizer que era próximo dele. Fui à casa dele, mas não era "amigo" dele. E ele era de outra geração, mais velho ainda que Toni [Negri], cerca de 25 anos mais velho que eu. Foi naquela época que comecei a estudar Deleuze, Foucault, Guattari, mas eu pouco os entendia.

GBG: Agora gostaria de entrar mais profundamente na sua obra. Seu primeiro trabalho foi Trabalho imaterial?

ML: Sim, quando chegamos aqui, começamos a repensar o conceito de trabalho. A primeira coisa que fizemos foi tentar uma redefinição de como o trabalho deveria ser considerado. E então inventamos essa categoria de trabalho imaterial, que depois eu praticamente nunca mais utilizei porque não estava convencido de que era certa.

GBG: Aqui no Brasil, sua obra mais conhecida é exatamente Trabalho imaterial, publicada inicialmente em 2001, dez anos após a publicação em francês. Mas eu digo que o Maurizio Lazzarato que escreveu Trabalho imaterial não é o mesmo Maurizio Lazzarato que escreveu Videofilosofia, ${ }^{7}$ cinco anos depois, por exemplo. Vi uma mudança muito grande nesses cinco anos que separam essas duas obras. Vejo poucas coisas

${ }^{7}$ LAZZARATO, M. Videofilosofia: La percezione del tempo nel postfordismo. Roma: Manifestolibri, 1996 (inédito em português). 
em comum no seu pensamento. Vejo que o senhor toma uma distância de Negri e deste conceito de trabalho imaterial. É correto este entendimento?

ML: Sim, eu tinha muitas dúvidas. Eu extraía algumas coisas do conceito de imaterial, mas deixava passar outras [importantes]. Por isso me distanciei deste conceito e praticamente nunca mais o utilizei. Então, só utilizei esse conceito naqueles artigos mesmo. Não me parecia corresponder ao que eu pretendia. Não entendia muito bem o porquê, mas agora tenho uma ideia bem clara de porque não funcionava. Depois, quando meus colegas tomaram o conceito de trabalho cognitivo, fui contra. A esta ideia de que o trabalho cognitivo era um desenvolvimento ainda mais avançado que o trabalho imaterial, fui totalmente contra. Discordava de pensar o capitalismo como capitalismo cognitivo, a centralidade do trabalho cognitivo, do trabalho imaterial e de sua hegemonia, eu pensava que não era possível [pensar dessa forma]. E depois procurei trabalhar em outras frentes, encontrar outras pistas. É verdade que, já no Videofilosofia, eu procurava outras coisas, me interessei pela tecnologia [...]. Porém, fundamentalmente, a solução eu encontrei mais tarde, muito mais tarde, por meio da relação com a dívida. Na realidade, o capitalismo contemporâneo não é um capitalismo cognitivo. Se existe alguma coisa que funciona de forma hegemônica não é o trabalho cognitivo nem o trabalho imaterial, já que o trabalho imaterial é uma tentativa de permanecer internamente no discurso marxista clássico, passando do trabalho marxiano, do trabalho dos operários, para um outro tipo de trabalho; portanto, ainda se procurava o sujeito [revolucionário], um novo tipo de sujeito político-social. Este tipo de abordagem não era, para mim, muito correto, seja do ponto de vista teórico, seja do ponto de vista político, porque efetivamente não determinava níveis de luta, de cristalização de luta social. No entanto, a questão do credor e devedor, ela sim, implica uma cristalização política. Podemos dizer da seguinte forma: o capitalismo mudou da luta de classe do trabalho, que era aquele clássico do final do século XIX 
e início do século $X X$, para um outro tipo de luta de classe, que é aquela do credor e do devedor, portanto, do capital financeiro.

GBG: Temas esses que o senhor desenvolve nas obras A fábrica do homem endividado ${ }^{8} \mathrm{O}$ governo do homem endividado. ${ }^{9}$

ML: Exato, isso me parece hoje mais correto do ponto de vista da análise do capitalismo. Não é que o trabalho tenha desaparecido. O trabalho existe, está sempre ali, existe uma multiplicidade de tipos de trabalho. Aquilo que se denomina por trabalho cognitivo, trabalho imaterial, é só uma parte [da categoria trabalho]. Existe o trabalho feminino, o trabalho operário, a escravidão, e o trabalho cognitivo e o trabalho imaterial não são, de forma alguma, hegemônicos sobre os outros tipos de trabalho. Pelo menos, até hoje não se viu, nem teoricamente, nem politicamente, uma luta de classes significativa, nos últimos quarenta anos, entorno do trabalho cognitivo. Eu nunca vi. Além disso, existe a luta dos intermitentes, que sigo proximamente e sobre a qual trabalhei muito, mas que, porém, não determina uma luta generalizada. Escrevi livros sobre este assunto: meus livros Intermitentes e precários ${ }^{10}$ e $O$ governo das desigualdades ${ }^{11}$ tratam disso. Acompanhei isso de forma muito próxima. E o único verdadeiro trabalho realizado sobre o "trabalho cognitivo" é aquele ali. Foi uma luta significativa e importante, mas não determina a hegemonia em relação a outros tipos de trabalho.

${ }^{8}$ LAZZARATO, M. La fabrique de l'homme endetté: Essai sur la condition néolibérale. Paris: Éditions Amsterdam, 2011 (inédito em português).

${ }^{9}$ LAZZARATO, M. Il governo dell'uomo indebitato: Saggio sulla condizione neoliberista. Roma: DeriveApprodi, 2013 (inédito em português).

${ }^{10}$ LAZZARATO, M.; CORSANI, A. Intermittents et précaires. Paris: Éditions Amsterdam, 2008 (inédito em português).

${ }^{11}$ LAZZARATO, M. O governo das desigualdades: Crítica da insegurança neoliberal. Trad. Renato Abramowicz Santos. São Carlos: EdUFSCar, 2011. 
|256 |

Entrevista com Maurizio Lazzarato

GBG: No livro O governo das desigualdades o senhor faz uma pesquisa prática na França com trabalhadores ditos "cognitivos", como artistas, etc.

ML: Sim, fiz duas, três pesquisas a esse respeito, pois trabalhei por cerca de dez anos com a coordenação dos "intermitentes e precários" de Paris e depois fiz duas pesquisas sociológicas sobre esse tipo de trabalho. Uma das duas pesquisas foi publicada no [livro] Intermitentes e precários. Depois escrevi outro livro, Experimentações políticas, ${ }^{12}$ que é um balanço teórico desta experiência. O livro O governo das desigualdades é o primeiro capítulo de Experimentações políticas. Nesse trabalho, verifiquei que os trabalhadores precários, que poderiam ser definidos "cognitivos" segundo a categoria dos meus amigos, na realidade não se reconheciam como trabalhadores cognitivos, mas sim como precários, como desempregados; por isso, para mim, essa teoria não funcionava. Então, do ponto de vista prático, não existe uma hegemonia com outros setores e é muito parcial como discurso. Continuei a analisar esse tipo de atividade, mas não como teoria geral. $\mathrm{O}$ que me interessava eram sobretudo os desempregados, os que têm a renda de sobrevivência na França... os considerados "marginais". De tudo isso eu fiz um trabalho importante de pesquisa sociológica.

GBG: Em que anos foram publicados esses dois livros?

ML: Intermitentes e precários em 2008 e Experimentações políticas em 2009. Mas antes, em 2002, eu escrevi o livro Poderes da invenção. ${ }^{13}$

\footnotetext{
${ }^{12}$ LAZZARATO, M. Expérimentations politiques. Paris: Éditions Amsterdam, 2009 (apesar de inédita em português, o primeiro capítulo desta obra aparece em $O$ governo das desigualdades).

${ }^{13}$ LAZZARATO, M. Puissances de l'invention: La psychologie économique
} 
GBG: Ele vai ser publicado em português?

ML: Esse livro eu não recomendaria muito [para estudar esse tipo de situação dos precários]. Existem algumas coisas interessantes, outras nem tanto. Eu estava procurando encontrar algumas soluções em termos da categoria do trabalho, e pensei ter encontrado em Gabriel Tarde a chave. Mas não é assim. Penso que a solução definitiva encontrei anos depois, com a relação credordevedor. Trabalho imaterial, precário, intermitente etc., são coisas importantes e que existem, porém, a articulação geral do tema passa diretamente pela relação do crédito e débito.

GBG: Esse entendimento o senhor explica no seu livro, partindo da obra de Nietzsche Genealogia da moral e dos primeiros escritos de Marx.

ML: Sim, exato. Na Europa e no mundo, a possibilidade de colocar o capitalismo em crise passa pela questão do débito, da gestão do débito, e não pelo trabalho. $\mathrm{O}$ trabalho não tem mais a força que tinha no século XIX no texto de Marx. Essa tentativa de continuar de maneira linear a questão do trabalho me deixava em um impasse. Consegui sair dessa "armadilha" do trabalho apesar de ainda continuar estudando-o. Não penso que a questão do trabalho cognitivo e do capitalismo cognitivo seja central, nem do ponto de vista teórico, nem do ponto de vista político.

GBG: O senhor aponta que o trabalho cognitivo é submetido à relação credor-devedor.

de Gabriel Tarde contre l'économie politique. Paris: Les empêcheurs de penser en rond, 2002 (inédito em português). 
| 258 |

Entrevista com Maurizio Lazzarato

ML: Exato, [o trabalho cognitivo] existe, mas está sob o jugo da relação credor-devedor. Essa tensão credor-devedor é o terreno para onde os capitalistas se deslocaram... não é só controlar o trabalho, mas controlar a população no seu conjunto, isto é, controlar a multiplicidade que constitui a população, ou seja, o trabalho, a reprodução, as minorias, os marginais, os precários. Por meio desse controle, eles conseguem controlar o conjunto da produção e da reprodução do capital, que não se consegue mais controlar apenas mediante o trabalho. Ao passo que, um tempo atrás, no capitalismo industrial, o trabalho era hegemônico, isso não acontece mais a partir da metade dos anos 1970. Meus amigos [do capitalismo cognitivo] continuam a pensar o capitalismo cognitivo, mas o que entendi recentemente é que, naquela época, quando trabalhei com o conceito de trabalho imaterial, nós abandonamos a categoria que era fundamental no operaismo, que era a recusa do trabalho. Ou seja, se tivéssemos reunido as categorias do trabalho imaterial com a questão da recusa do trabalho, as coisas teriam sido mais claras. No entanto, juntamos o trabalho e a criatividade, o que, para mim, é errado do ponto de vista político e conceitual. Já juntando o trabalho e a recusa do trabalho, pensando que o trabalho é sempre trabalho debaixo do comando capitalista, e isso é cada vez mais evidente. Dessa forma, superestimamos a criatividade, a cooperação, a possibilidade de determinar o próprio tempo de trabalho etc., o que não é nada verdadeiro. Ao invés disso, se tivéssemos permanecido nessa categoria de trabalho [imaterial] e a tivéssemos adaptado aos novos tipos de atividade que se desenvolviam, teria sido mais claro. No entanto, tomar o trabalho e a criatividade sozinhos determinou, para mim, confusão política e também teórica. Por isso seria importante tomar novamente a recusa do trabalho, colocar mais ênfase na recusa do trabalho; a criatividade não dá a possibilidade de opor-se de maneira radical e precisa ao comando capitalista. É necessária uma outra dinâmica, ligada à recusa. É necessário dizer "não". Parece-me que o discurso do trabalho imaterial é ainda muito ligado à criatividade. Parece que meus amigos brasileiros, apesar de eu não acompanhar muito, penso que fazem um discurso muito ligado à criatividade. Vi que 
saiu um livro chamado Capitalismo cognitivo... ${ }^{14} \mathrm{O}$ capitalismo nunca é criativo. O problema do capitalismo não é a criatividade, o problema do capitalismo é como acumular-se e como acumular.

GBG: É a recusa do trabalho que o senhor estuda, em seu último livro, por meio da obra de Marcel Duchamp. $\cdot^{15}$ A recusa como um ato, não como um ócio.

ML: Exato, a recusa como uma maneira de agir. Uma outra temporalidade, a temporalidade do ócio. Pensar uma temporalidade diferente da temporalidade na qual o capital nos obriga a movermos-nos. Portanto, o ócio como uma possibilidade de romper, de dizer não, de recusar a temporalidade do capital. E depois a possibilidade de desfrutar outras temporalidades. Neste livro, faço duas críticas ao conceito de trabalho criativo desenvolvido na França. Uma delas se dirige contra o sociólogo francês Pierre-Michel Menger e outra se dirige contra Boltanski e Chiapello, do livro O novo espírito do capitalismo. ${ }^{16}$ Fiz a crítica deste livro e sobre o conceito de trabalho criativo, que para mim é problemático. Agora estou escrevendo um novo livro com um amigo.

GBG: Como vai se chamar?

${ }^{14}$ COCCO, G.; GALVÃO, A.P.; SILVA, G. (orgs.). Capitalismo cognitivo: Trabalho, redes e inovação. Rio de Janeiro: DP\&A, 2003.

${ }^{15}$ LAZZARATO, M. Marcel Duchamp et le refus du travail. Paris: Prairies Ordinaires, 2014 (inédito em português).

16 BOLTANSKI, L.; CHIAPELLO, E. O novo espírito do capitalismo. Trad. Ivone C. Benedetti. Rio de Janeiro: WMF Martins Fontes, 2009. 
ML: Guerras e capital - a palavra "guerras" no plural -, em que discorro sobre a relação das guerras com o capital, pensando a relação entre moeda, Estado e a guerra. ${ }^{17}$ Tomar a guerra como elemento constitutivo do capital. Essa relação foi um pouco abandonada [do ponto de vista teórico], mas se você pensar na história do capitalismo do início da conquista das duas Américas, América do Norte e América do Sul, a guerra é um elemento fundamental. Portanto, estou procurando construir essa relação da guerra com o capital a partir do início do capitalismo, acumulação primitiva, depois o capital financeiro, as duas guerras mundiais, a guerra fria, para chegar até hoje, quando a guerra continua no centro. Portanto, é impossível pensar o capital sem pensar a máquina de guerra.

GBG: Pensar a guerra como elemento constitutivo do capital.

ML: Exatamente.

GBG: A guerra, a dívida, as tecnologias, vejo que o senhor está desmembrando as faces do capital.

ML: Sim, e agora vejo a guerra como elemento central. Penso que o capitalismo contemporâneo está, de certa forma, acentuando esses elementos de crise econômica e política que tendem a reconfigurar uma nova forma de guerra. A guerra não é igual, a guerra mudou, a relação capital e guerra mudou ao longo dos anos e agora também está se modificando com o neoliberalismo. O neoliberalismo com o capital financeiro utiliza uma nova forma de guerra para funcionar. Aquilo que está acontecendo aqui na Europa com a Grécia é a evidência de como a luta de classe

${ }^{17}$ LAZZARATO, M.; ALLIEZ, E. Guerres et capital. Paris: Éditions Amsterdam, 2016 (inédito em português). 
se cristalizou na questão da dívida. Na realidade, o que estão operando contra a Grécia é uma forma de guerra moderna, e é por isso que estou trabalhando com este tema.

GBG: Sobre o livro A política do acontecimento, ${ }^{18}$ foi sua tese de doutorado?

ML: Não, foi Videofilosofia.

GBG: E onde a defendeu?

ML: Em Saint Denis, [Université] Paris 8. da Calábria.

GBG: E A política do acontecimento foi escrita na Universidade

ML: Foi um curso de uma semana com doutorandos e resolvi escrever aquele livro. Então ele foi publicado em 2004, mas o curso foi um ou dois anos antes.

GBG: Este é, no Brasil, o seu segundo livro mais conhecido, mas publicado com o título de As revoluções do capitalismo.

ML: Sim, é um título que eu não queria, mas o editor queria. Eu gostaria que se chamasse "A política do acontecimento", mas foi o editor que quis.

${ }^{18}$ LAZZARATO, M. La politica dell'evento. Cosenza: Rubbettino, 2004. 
GBG: Tem um tanto de Gabriel Tarde.

ML: Gabriel Tarde pode ser útil por alguns aspectos, como a dimensão micropolítica. No entanto, no discurso macropolítico, como ele não pensava que o capitalismo existisse, não é válido. Mas Tarde é interessante porque tinha a ideia de realizar o ciclo trabalho não a partir da fábrica, mas a partir da produção de vida. Mas sobre o nível macroeconômico, como teoria para conhecer o capitalismo, é algo que não vai bem. Certos aspectos são úteis, outros são danosos.

GBG: Qual a importância para o senhor, hoje, no capitalismo de 2015, das inferências que o senhor expôs no seu livro Signos, máquinas, subjetividades? Acredito que a questão da sujeição social e servidão maquinica, que o senhor fez aflorar de forma brilhante, não era tão clara nem mesmo para Deleuze e Guattari, ${ }^{19}$ talvez porque não tenham vivido todo esse desenvolvimento tecnológico que existe hoje.

ML: O conceito de servidão maquínica é interessante porque implica muitas coisas. Se eu fosse escrever agora, diria que é importante porque a servidão maquínica reúne os conceitos de servidão, tomada por empréstimo da informática, e o conceito de máquina, uma das fontes do qual é [Lewis] Mumford. ${ }^{20}$ E a primeira máquina social foi a máquina do império egípcio. O conceito junta as formas de escravidão com as formas modernas de produção. Esse conceito reúne a produção que passa pelas formas modernas de produção, as formas modernas de comunicação,

${ }^{19}$ Os autores exploram a questão da servidão maquínica em DELEUZE, G.; GUATTARI, F. Mil Platôs: Capitalismo e esquizofrenia, vol. 2. Trad. Ana Lúcia de Oliveira e Lúcia Cláudia Leão. Rio de Janeiro: Ed. 34, 1995.

${ }^{20}$ MUMFORD, L. The Myth of the Machine, vol. 1: Technics And Human Development. New York: Harcourt, Brace and World, 1967. 
mas também uma forma moderna de neo-escravidão. Estas coisas podem ser úteis junto com esse conceito, isso é o que me parecia importante; e penso que deveria refletir ainda sobre isso, mesmo se eles publicaram isso em 1980. O conceito de servidão maquínica, o conceito de máquina é importante: a máquina social, máquina técnica, tem a máquina da guerra, e a servidão maquínica, uma maneira de subordinar as pessoas por meio da comunicação, já que se pode falar de servidão maquínica através dos meios eletrônicos, mas também se pode falar da servidão maquínica com relação à reforma da produção industrial, por exemplo; e ao mesmo tempo as máquinas como esse conceito de máquina social, como a escravidão do império egípcio. E, ao mesmo tempo, tem a questão da sujeição, a produção de subjetividade que acontece com esse dispositivo. E isso me parecia mais interessante que o trabalho cognitivo, intelectual. Neste novo livro que estou escrevendo, estou desenvolvendo um pouco o conceito de como se pensar a questão da máquina sob uma maneira diferente de como se pensa hoje.

\section{GBG: Como uma máquina social?}

ML: Sim, como máquina social e máquina de guerra. E esse conceito de máquina de guerra foi desenvolvido em Mil Platôs [de Deleuze e Guattari]. 